\title{
PEMAHAMAN KONSEP TEOLOGI HINDU (PERSPEKTIF PENDIDIKAN AGAMA HINDU)
}

\author{
Ni Wayan Ramini Santika \\ Institut Agama Hindu Negeri Tampung Penyang Palangkaraya \\ bawiayahfda@gmail.com
}

\begin{abstract}
Riwayat Jurnal
Artikel diterima

Artikel disetujui :-
\end{abstract}

\section{Abstrak}

Dalam kehidupan beragama khususnya agama Hindu yang memiliki suatu Pemahaman Konsep Teologi Hindu yang bersumber daripada Kitab Suci Veda dan Kitab Suci Panaturan, karena kitab suci sebagai pedoman umat Hindu dalam memperkuat keimanan tentang pengetahuan Ketuhanan. Agama Hindu mengembangkan ajarannya sesuai dengan desa (tempat), kala (waktu/penentuan hari baik atau buruk) dan patra (keadaan sosial ekonomi, situasi dan kondisi). Selain itu, dalam pelaksanaan ajaran agama Hindu juga selalu berpegang pada Tiga Kerangka Dasar Agama Hindu yaitu Tattwa (filsafat), etika (tata susila) dan ritual (upacara). Ketiga kerangka ini merupakan sebagai dasar bagi setiap umat Hindu dalam usahanya untuk mencapai ketenangan dan ketentraman dalam keyakinanya. Aspek tattwa atau filsafat agama merupakan inti ajaran Agama Hindu, sedangkan aspek susila atau etika merupakan pelaksanaan ajaran agama dalam kehidupan masyarakat sehari-hari.

Aspek upacara atau ritual agama merupakan yadnya, persembahan atau pengorbanan suci yang tulus ikhlas kehadapan Ida Sang Hyang Widhi Wasa. Ketiga aspek tersebut merupakan suatu kesatuan yang utuh dan tidak dapat dipisah-pisahkan. Karena itu ketiga kerangka dasar agama tersebut harus dipahami, mengingat ketiganya saling berkaitan. Memahami atau tidak memahami salah satu aspek, dapat mengakibatkan pemahaman terhadap Agama Hindu menjadi tidak lengkap dan bahkan bisa mengaburkan atau memberi pengertian yang keliru terhadap Agama Hindu.. Pendidikan Agama Hindu diberikan pada peserta didik diharapkan agar menjadi orang yang bertaqwa kepada Tuhan Yang Maha Esa. Dengan Pendidikan Agama Hindu dapat menjalankan dan mengamalkan ajaran Agama Hindu sehingga terbentuknya budi pekerti yang luhur dan berakhlak yang mulia.

Kata Kunci : Pemahaman, Konsep Teologi Hindu, Pendidikan Agama Hindu

\section{Pendahuluan}

Pendidikan yang berkualitas adalah salah satu cara untuk meningkatkan daya saing sebuah bangsa yang kita sadari pendidikan memiliki peran sangat penting. Pemerintah Indonesia terus 
berupaya dalam meningkatkan pemerataan kualitas dan layanan pendidikan. Dalam Undang-Undang Nomor 20 tahun 2003 tentang Pendidikan Nasional dalam pertimbangannya menyatakan bahwa Undang-Undang Dasar Negara Republik Indonesia tahun 1945 mengamatkan pemerintah mengusahakan dan menyelenggarakan suatu sistem pendidikan Nasional yang meningkatkan keimanan dan ketakwaan kepada Tuhan Yang Maha Esa serta akhlak mulia dalam rangka mencerdaskan kehidupan bangsa yang diatur dengan Undang-Undang bahwa Sistem Pendidikan Nasional harus mampu menjamin kesempatan pendidikan, peningkatan mutu, serta relevansi dengan efesiensi manajemen pendidikan untuk menghadapi tantangan sesuai dengan tuntutan perubahan pendidikan secara terencana, terarah dan berkesinambungan. Sistem pendidikan nasional adalah keseluruhan komponen yang saling terkait dan terpadu untuk mencapai tujuan pendidikan nasional. Pendidikan nasional adalah pendidikan yang berdasarkan Pancasila dan Undang-Undang Dasar tahun 1945, yang berakar pada nilai-nilai agama, Kebudayaan Nasional dan tanggap terhadap tuntutan jaman (Sisdiknas dalam Tim Penyusun, 2007:6). Agama Hindu merupakan salah satu agama yang diyakini di Indonesia selain keyakinan agama yang ada. Sebagai bagian dari keyakinan Bangsa Indonesia yang sangat majemuk, di dalam menjalani ajaran agamanya umat Hindu sama seperti agama lain yang diakui di Indonesia. Agama Hindu di dalam mengembangkan ajarannya sesuai dengan desa (tempat), kala (waktu/penentuan hari baik atau buruk) dan patra (keadaan sosial ekonomi, situasi dan kondisi). Selain itu, pelaksanaan ajaran agama Hindu juga selalu berpegang pada Tiga Kerangka Dasar Agama Hindu yaitu tattwa (filsafat), etika (tata susila) dan ritual (Upacara). Ketiga kerangka ini merupakan sebagai dasar bagi setiap umat Hindu dalam usahanya untuk mencapai ketenangan dan ketentraman dalam keyakinanya. Aspek tattwa atau filsafat agama merupakan inti ajaran Agama Hindu, sedangkan aspek susila atau etika merupakan pelaksanaan ajaran agama dalam kehidupan masyarakat sehari-hari. Aspek upacara atau ritual agama merupakan yadnya, persembahan atau 
pengorbanan suci yang tulus ikhlas kehadapan Ida Sang Hyang Widhi Wasa.

Ketiga aspek di atas merupakan suatu kesatuan yang utuh dan tidak dapat dipisah-pisahkan. Karena itu ketiga kerangka dasar agama tersebut harus dipahami, mengingat ketiganya saling berkaitan. Memahami atau tidak memahami salah satu aspek, dapat mengakibatkan pemahaman terhadap Agama Hindu menjadi tidak lengkap dan bahkan bisa mengaburkan atau memberi pengertian yang keliru terhadap Agama Hindu. Oleh karenanya, barang siapa ingin mempelajari Agama Hindu hendaknya mendalami ketiga kerangka dasar agama tersebut.

Bagi umat Hindu sendiri memahami dan mendalami ketiga aspek tersebut diatas tentu akan menjadi sangat penting. Janganlah hanya berpegang kepada salah satu aspeknya saja misalnya aspek upakara dan upacaranya saja. Usahakanlah mempelajari, menghayati dan mengamalkan bukan saja aspek upakara dan upacaranya, tetapi juga aspek filosofi dan susilanya. Dengan demikian, maka akan terdapat keseimbangan dalam pemahaman dan pelaksanaan upakara/upacara, filosofi dan susilanya.

\section{Pembahasan}

\subsection{Pemahaman}

Pemahaman didefinisikan proses berpikir dan belajar. Pemahaman menurut Kamus lengkap Bahasa Indonesia yaitu proses, perbuatan dan cara memahami. Indikator pemahaman sama artinya dengan memahami sesuatu berarti seseorang dapat mempertahankan, membedakan, menduga, menyimpulkan dan menuliskan kembali. Pemahaman yang dimaksud adalah Konsep Teologi Hindu. Pemahaman Konsep Teologi Hindu yang bersumber dari pada Kitab Suci Veda dan Kitab Suci Panaturan, Kitab Suci sebagai pedoman umat Hindu dalam memperkuat keimanan tentang pengetahuan Ketuhanan.

\subsection{Teologi Hindu}

Etimologi Teologi, ada banyak definisi (terminologi) tentang istilah teologi ini, namun pada hakikatnya semua definisi ini mengarah pada satu pengertian, yaitu pengetahuan "Tuhan". Sebagaimana pendapat seorang teolog besar dari Roma Katholik yang bernama Albert, ia menguraikan bahwa : Istilah "teologi" secara harafiah berarti studi 
mengenai Allah. Yang berasal dari kata Yunani theos, yang berarti Tuhan dan akhiran-ology dari kata Yunani logos yang berarti wacana, teori, atau penalaran. Selain definisi tersebut pendapat lain yaitu Agustinus dari Hippo mendefinisikan bahwa teologi berasal dari bahasa Latin, yaitu theologia, sebagai penalaran atau diskusi mengenai Ketuhanan, selain itu Richard Hooker mendefinisikan "theology" dalam bahasa Inggris sebagai "ilmu tentang hal-hal yang ilahi”. Juga secara umum, teologi adalah studi iman agama, praktik, dan pengalaman atau spiritualitas.

Ontologi teologi adalah sebuah ilmu pengetahuan, dan sebagai ilmu pengetahuan, teologi harus mampu membuktikan kebenaran ilmu pengetahuannya. Pembuktian teologis, walaupun melibatkan daya nalar manusia, namun teologi tetap bertumpu pada pewahyuan dan kebenaran-kebenaran iman (Donder, 2009:1-14).

Pengertian tentang Tuhan Yang Maha Esa dalam Brahma sutra sebagai berikut : Janmadyasya yatah (I.1.2), yang oleh Swami Sivananda diterjemahkan sebagai berikut : janmadi adalah Asal mula dan lain-lain (pemeliharaan dan peleburan); asya adalah dari dunia ini; yatah adalah dari mana. Brahman adalah asal muasal dari alam semesta dan segala isinya. Tuhan Yang Maha Esa yang disebut Brahman ini merupakan asal mula segalanya. Beberapa penjelasan tentang Tuhan Yang Maha Esa merupakan asal mula segalanya dalam kitab suci Rg Veda, sebagai berikut :

\section{Purusa evedam sarvam yadbhutam yacca bhavyam, utamrtatvasyesa no yadannenati rohati.} Artinya:

Tuhan sebagai wujud kesadaran agung merupakan asal dari segala yang telah dan yang akan ada. Ia adalah raja di alam yang abadi dan juga di bumi ini yang hidup dan berkembang dengan makanan (Rgveda X.90.2).

\section{Demikian pula, Tuhan Yang} Maha Esa sebagai sumber segala dan sumber kebahagiaan hidup, dinyatakan pula di dalam mantra Atharvaveda, sebagai berikut :

Yo bhutam ca bhavyam ca sarvam yas cadhitisthati, svar yasyaca kevalam tasmai jyesthaya Brahmane namah. Artinya :

Tuhan Yang Maha Esa hadir dimana-mana, asal dari segala yang telah ada dan yang akan ada. Ia penuh dengan rakhmat dan 
kebahagiaan. Kami memuja Engkau, Tuhan Yang Maha Tinggi (Atharvaveda X.8.1).

Mendekatkan diri kepada Tuhan Yang Maha Esa merupakan hal yang wajib untuk dilakukan guna mewujudkan kesejahtraan dan kebahagiaan yang sejati. Jalan kebaktian kepada Tuhan Yang Maha Esa adalah jalan yang paling mudah diikuti oleh umat manusia pada umumnya. Tuhan Yang Maha Esa merupakan sumber kehidupan dalam kitab suci Yajur Veda XXVI.3, sebagai berikut :

Om bhur bhuvah svah

Tat savitur varenyam

Bhargo devasya dhimahi,

Dhiyo yo nah pacodayat.

Artinya:

Ya Tuhan Yang Maha Esa, Sang Hyang Widhi Wasa, Engkau adalah sumber kehidupan, sumber kecerdasan dan sumber kebahagiaan, pencipta alam semesta. Kami memuja kilauan-Mu yang bercahaya. Kami mohon bersedialah Engkau memberikan tuntunan yang benar kepada kecerdasan budi pekerti kami (Titib, 1996:204).

Persembahan kepada Tuhan Yang Maha Kuasa sebagai Tuhan Sang Maha Pencipta yang menguasai bumi dan langit, dinyatakan dalam kitab suci $\mathrm{Rg}$ Veda X.121.1, sebagai berikut :
Hiranyagarbhah samavartatagre

Bhutasya jatah patireka asit, Sa dadhara prthivim dyam utemam Kasmai devaya havisa vidhema Artinya:

Siapakah yang kami puja dengan persembahan kami yang suci yang ada dalam permulaan, yang diwujudkan sebagai Tuhan Sang Maha Pencipta yang menguasai bumi dan langit (Titib, 1996:205).

Tuhan Yang Maha Esa sebagai sumber kekuatan-kekuatan jiwa yang bayangan-Nya adalah keabadian dan kematian, dinyatakan dalam kitab suci Rgveda X.121.2 sebagai berikut :

Ya atmada balada yasya visva Upasate prasisam yasya devah Yasya chayamrtam yasya mrtyuh Kasmai devaya havisa vidhema Artinya:

Siapakah yang akan kami puja dengan persembahan ini? Ia yang memberikan kekuatan jiwa dan tenaga yang hukum-Nya dipatuhi oleh seluruh alam semesta, dipatuhi oleh kekuatan kosmos yang bayangan-Nya adalah keabadian dan kematian (Titib, 1996:205).

\footnotetext{
Konsep Ketuhanan yang menyatakan bahwa Tuhan Yang Maha Esa merupakan awal segala kejadian terkandung dalam kitab suci panaturan yang merupakan kitab suci Hindu kaharingan, terdapat pada Panaturan pasal 1 ayat 1 sebagai berikut :
} 
Hemben huran tutuk panambalun tambun, baya ije atun IE ije tamparan taluh handiai, JAI panapatuk sukup simpan, hasambalut umba ambun ije dia bajahuntun tanduk, basakupa dengan enun isen baterus kening, hinje hasambalut umba kahain kuasae belum japa jimat maharing. Artinya:

Jaman dahulu kala, permulaan segala masa, yang ada Ia adalah Awal segala Kejadian, Ia yang maha sempurna diliputi oleh Kekuatan dan KekuasaanNya, menyatu didalam Keagungan dan KemuliaanNya

(MB-AHK, 2009:1).

Tuhan Yang Maha Esa adalah awal segala kejadian, yang memperlihatkan Kebesaran dan KekuasaanNya, dinyatakan dalam kitab suci Panaturan, Pasal 1 ayat 2, sebagai berikut :

Ie ije tamparan taluh handiai mukei kahain kuasae, Jai panapatuk sukup simpan murai japa jimat tanteng, hayak auh Nyahu Batengkung Ngaruntung Langit, homboh Malentar Kilat Basiring Hawun, palus ambun ije dia bajahuntuk tanduk, enun basansinep isen baterus kening, badandang manjadi balawa hayak barasih, lendalendang, linge-lingei, hayak Ie hamauh mananggare arepe : Aku tuh Ranying Hatalla, mijen Balai Bulau Napatah Hintan, Balai Hintan Napatah Bulau, mijen Tasik
Malambung Bulau, marung Laut Bapantan Hintan.

Artinya :

Ia adalah awal segala kejadian, memperlihatkan Kebesaran dan KekuasaanNya; Ia yang maha sempurna; Menyatakan Keagungan dan KemuliaanNya, dan bersama dengan itu, bergetarlah alam semesta laksana Guntur menggelegar Langit, Petir dan Halilintar menggetar semesta alam, maka memancarlah Cahaya Terang yang bersih suci, menghalau kegelapan alam, serta Ia yang awal segala kejadian, berfirman dan menyatakan diriNya : Aku inilah Ranying Hatlla yang bertahta pada balai bulau napatah bulau, dikelilingi tasik malambung bulau laut bapantan hintan (MB-AHK, 2009:1).

Tuhan Yang Maha Esa atau Ranying Hatalla yang memiliki cahaya kehidupan yang kekal abadi, dinyatakan dalam kitab suci Panaturan, Pasal 1 ayat 3 sebagai berikut :

Aku tuh Ranying Hatalla ije paling kuasa, tamparan taluh handiai tuntang kahapuse, tuntang kalawa jetuh iete kalawa pambelum, ije inanggareKu gangguran area bagare hintan kaharingan.

Artinya:

Aku inilah Ranying Hatalla Yang Maha Kuasa, awal dan akhir segala Kejadian dan cahaya Kemuliaan-Ku yang terang, bersih dan suci adalah cahaya kehidupan yang kekal abadi dan aku sebut ia 
hintan kaharingan (MB-AHK, 2009:1).

Tuhan Yang Maha Esa atau Ranying Hatalla memiliki kekuatan jiwa yang bayanganNya adalah keabadian. Panaturan, Pasal 1 ayat 5 menyatakan sebagai berikut :

Intu hete Ie nyantah bulau balawan tanduk, tampajahen sambil ngantau, Jai niling rabia rantunan kening, nureng ulang pajambilei, eleh benyem nyalantinau buang; Mariarae tiai bulau balawan tanduk, nuntun hila ngiwa; Hete taratuntue atun ampin pahaliar tingang ije sama kilau Ie.

Artinya:

Disanalah Ia melihat sekelilingNya, memperhatikansekitarNya, sepi, sunyi, senyap; Ia memandang kebawah, disitu terlihat oleh-Nya, ada suatu wujud serupa Ia (MBAHK, 2009:2).

Tuhan Yang Maha Esa atau Ranying Hatalla memiliki kekuatan jiwa yang bayanganNya adalah zat yang maha mulia. Panaturan, Pasal 1, ayat 6 menyatakan sebagai berikut :

Ranying Hatalla nuntun pahaliar tingang, nureng nyababeneng tanduk, handung katawae hete puna pahalingei bitie, hayak Ie mananggare gangguranan area bagare jatha balawang bulau, kanaruhan ba-pager hintan, mijen papan malambung bulau, marung laut bapantan hintan.

Artinya:
Ranying Hatalla, memperhatikan wujud itu dengan sungguhsungguh, bahwa itu adalah bayanganNya sendiri, dan Ia memberikan nama kepada bayanganNYA itu, adalah jatha balawang bulau, kanaruhan bapager hintan (zat yang maha mulia), yang berada didalam papan malambung bulau, bertachta pada laut bapantan hintan (MB-AHK, 2009:2).

Berdasarkan kutipan daripada Kitab Suci Veda dan Kitab Suci Panaturan tersebut di atas yang menyatakan tentang kemaha kuasaan dan keberadaan Tuhan Yang Maha Esa.

\subsection{Perspektif Pendidikan Agama Hindu}

Pendidikan Agama Hindu merupakan suatu pendidikan yang sangat penting, Pendidikan Agama Hindu ini bertujuan memberikan pengajaran mental dan spiritual bagi si anak. Pendidikan Agama Hindu telah diajarkan pada setiap sektor pendidikan, dimulai dari tingkat dasar sampai pada tingkat perguruan tinggi. Sesuai dengan UUD 1945 pada pasal 29 ayat 1 dan 2 serta Pancasila sebagai dasar falsafah bangsa Indonesia, maka pendidikan agama merupakan segi pendidikan yang utama yang menjadi dasar semua segi pendidikan lainnya. 
Pendidikan Agama Hindu diberikan pada peserta didik diharapkan agar menjadi orang yang bertaqwa kepada Tuhan Yang Maha Esa. Dengan Pendidikan Agama Hindu dapat menjalankan dan mengamalkan ajaran Agama Hindu sehingga terbentuknya budi pekerti yang luhur dan berakhlak yang mulia, sebagaimana yang dinyatakan dalam Sarasamuscaya yang menyatakan sebagai berikut :

Apan iking dadi wwang, uttama juga ya nimitaning mangkana,

Wenang ya tumulang awaknyasangking sangsar, mangkasadhana

Subhakarma, hinganing kottamaning dadi wwang ika (Sarasamuscaya,4)

Artinya:

Menjelma menjadi manusia itu adalah sungguh-sungguh utama, Sebabnya demikian, karena ia dapat menolong dirinya dari

keadaan sengsara (lahir dan mati berulang-ulang) dengan jalan

berbuat baik, demikian keuntungannya menjadi manusia (Kajeng,dkk,2003:9).

Dari kutipan Sarasamuscaya di atas, bahwa kehidupan itu sebagai proses pendidikan yang mana untuk memperbaiki diri sehingga tercapainya kesempurnaan hidup yang disebut
"Moksartham Jagadhita ya ca iti Dharma”.

Dalam Ajaran Agama Hindu terdapat nilai pendidikan ke dalam tiga ranah yang tak dapat dipisahkan antara satu dengan yang lainnya yaitu terurai dalam tiga kerangka dasar Agama Hindu yang terdiri dari Tattwa (Filsafat), Susila (Etika) dan Upacara.

\section{Pengertian Tattwa}

Tattwa berasal dari bahasa Sanskerta yaitu "Tatwa" kemudian setelah di Indonesiakan menjadi "Tattwa". Tattwa memiliki pengertian seperti : kebenaran, kenyataan, hakekat hidup, sifat krodati, dan segala sesuatunya bersumber dari kebenaran sejarah atau cerita yang diceritakan dengan jujur tentang sifat kebaikan maupun keburukan. Disamping kata Tattwa juga terdapat kata Tattwadyatmika (tentang Tuhan), Tattwadnyana (hekekat hidup), Tattwakmrta (dasar kehidupan), Tattwapadesagama (ajaran kenyataan dan agama). Aspek Tattwa merupakan inti dari ajaran Agama Hindu (Warta, 2007:1)

2. Pengertian Susila

Susila atau Etika agama berasal dari kata "su" yang artinya baik dan "sila" yang artinya tingkah laku. Susila agama 
berarti aturan-aturan yang baik mengenai tingkah laku yang harus dijadikan pedoman hidup oleh manusia yang beragama, khususnya umat Hindu. Ajaran Susila (etika) memegang peranan sangat penting dalam kehidupan manusia. Dengan ajaran Susila ini manusia akan dapat membina hubungan yang selaras, harmonis dan rukun antara sesamanya dan makhluk-makhluk hidup lainnya (Suhardana, 2010: 31)

\section{Pengertian Susila menurut} pandangan Agama Hindu adalah tingkah laku hubungan timbal balik yang selaras dan harmonis antara sesama manusia dan alam (lingkungan) yang berlandaskan atas korban suci (Yajna), keikhlasan dan kasih sayang.

Ajaran Etika tata susila Hindu merupakan ajaran tingkah laku yang baik dan benar bertujuan untuk terciptanya kebahagiaan hidup dan keharmonisan hubungan antara manusia dengan Tuhan, antara manusia dengan manusia dan manusia dengan lingkunganya. Dalam Kitab Suci Weda, ajaran tata susila itu mencakup berbagai bidang yang sangat luas antara lain tentang kebenaran.

Kebenaran dan kejujuran (satyam) merupakan prinsip dasar hidup dan kehidupan manusia Hindu. Dengan melaksanakan ajaran kebenaran dan kejujuran, maka hidup dan kehidupan seseorang akan diselamatkan dari berbagai mala petaka. Ikutilah jalan kebenaran dan kejujuran itu yang dikutip dari Yayur Veda X.121.2 I.5 di bawah ini

Agne vratapate vratam carisyami Tacchakeyam tanme radhyatam Idam aham anrtat satyam upaimi Yayurveda I.5

Artinya :

Ya Sang Hyang Agni, penguasa peraturan-peraturan suci, Kami akan menjalankan janji kebenaran itu. Semoga kami dimahkotai dengan keberhasilan dalam menjalankan janjiku. Kami menderapkan langkah dengan tegap pada jalan kebenaran, dengan menahan diriku sendiri dari kebohongan (dusta) (Titib, 1996:310).

\section{Pengertian Upacara}

Upacara atau ritual agama merupakan kerangka dasar yang ketiga dari Agama Hindu. Upacara berasal dari dua suku kata, yaitu : Upa dan Cara. Upa artinya dekat atau mendekat. Dan Cara dari urutan kata "Car" yang memiliki arti harmonis, seimbang dan selaras. Dengan keseimbangan, keharmonisan dan keselarasan dalam diri, kita mendekatkan diri dengan Tuhan Yang Maha Esa. 
Sebelum kita mendekatkan kepada-Nya, hendaknya terlebih dahulu kita dapat menciptakan keseimbangan dan keselarasan serta keharmonisan dalam diri kita, agar dapat terwujudnya keharmonisan dengan Tuhan Yang Maha Esa (Wijayananda,2004:49).

Dengan upacara rasa bakti menjadi semakin meningkat, upacara penting untuk mensucikan diri asal dilaksanakan dengan penuh keikhlasan berkorban dan bebas dari pamrih sesuai dengan kutipan sloka Bhagawadgita di bawah ini.

Yajna dana tapah karma

Na tyajyam karyam eva tat,

Yajno danam tapas caiva

Pavanani manisinam.

Bhagawadgita XVIII.5.

Artinya:

Kegiatan berkurban, bersedekah dan tapa, jangan diabaikan

Melainkan harus dilakukan sebab yajna, sedekah dan tapa

Brata adalah pensuci bagi orang arif bijaksana" (Pudja, 1999:405).

Etany api tu karmani

Sangam tyaktva phalani ca, Kartavyaniti me partha

Niscitam matam uttamam.

Bhagawadgita XVIII.6

Artinya:

Tetapi kegiatan inipun harus dilakukan dengan jalan melepaskan ikatan dan keinginan akan pahalanya; wahai
Arjuna, Inilah ketetapan dan pandangan-Ku yang terbaik (Pudja, 1999:405).

Demi bakti kehadapan Tuhan umat Hindu ikhlas mempersembahkan segala sesuatu yang mereka miliki demi bakti kepada Tuhan yang dicintainya.

\section{Penutup}

\subsection{Simpulan}

1. Pemahaman konsep teologi Hindu sangat penting dengan cara sebenarnya keyakinan tentang Ketuhanan adalah merupakan keyakinan rohani yang ada pada setiap individu. Sebagai makhluk yang terbatas, manusia berkeyakinan ada suatu kekuatan diluar kekuatan dirinya, serta diluar jangkauan manusia yang dapat memberikan sinar hidup pada setiap makhluk.

2. Aspek tattwa atau filsafat agama merupakan inti ajaran Agama Hindu, sedangkan aspek susila atau etika merupakan pelaksanaan ajaran agama dalam kehidupan masyarakat seharihari. Aspek upacara atau ritual agama merupakan yadnya, persembahan atau pengorbanan suci yang tulus ikhlas kehadapan Ida Sang Hyang widhi Wasa. 
3. Pendidikan Agama Hindu diberikan pada peserta didik diharapkan agar menjadi orang yang bertaqwa kepada Tuhan Yang Maha Esa. Dengan Pendidikan Agama Hindu dapat menjalankan dan mengamalkan ajaran Agama Hindu sehingga terbentuknya budhi pekerti yang luhur dan berakhlak yang mulia

\subsection{Saran - Saran}

Menanamkan pemahaman konsep teologi Hindu sejak dini pada anak-anak agar lebih memperkuat keyakinananya. Diharapkan kepada seluruh umat masyarakat Hindu terutama generasi muda agar selalu meningkatkan keyakinan/kepercayaan terhadap ajaran Agama dan menjadikan pedoman hidup dalam pergaulan sehari-hari.

\section{Daftar Pustaka}

Donder, I Ketut. 2006. Brahmavidya Teologi Kasih Semesta. Surabaya : Paramita.

Kajeng dkk, I Nyoman. 1999. Sarasamuccaya. Surabaya : Paramita.

MBAHK. 2009. Panaturan. Palangkaraya.

Pudja. 1999. Theologi Hindu (Brahma Widya). Surabaya : Paramita.

1999. Bhagawad Gita (Pancama Veda). Surabaya : Paramita.
Suhardana, K.M. 2006. Pengantar Etika dan Moralitas Hindu, Bahan Kajian Untuk Memperbaiki Tingkah Laku. Surabaya : Paramita.

Tim Penyusun. 2007. Pendidikan Agama Hindu di Perguruan Tinggi, Surabaya : Paramita.

Titib, I Made. 2003. Teologi dan SimbolSimbol dalam Agama Hindu, Surabaya : Paramita. . 2003. Veda Sabda Suci Pedoman Praktis Kehidupan. Surabaya : Paramita.

Watra, I Wayan. 2007. Pengantar Filsafat Hindu (Tattwa I). Penertbit Paramita. Surabaya

Wijayananda, Ida Pandita Mpu Jaya. 2004. Makna Filosofis Upacara dan Upakara dalam Kehidupan. Surabaya : Paramita. 